\title{
Ontological \\ Investigations of a \\ Pragmatic Kind? \\ A Reply to Lauer
}

Philosophy of the Social Sciences

202I, Vol. 5I(I) 3-12

(C) The Author(s) 2020

Article reuse guidelines:

sagepub.com/journals-permissions DOI: $10.1177 / 0048393120916134$

journals.sagepub.com/home/pos

(S)AGE

\section{Simon Lohse'}

\begin{abstract}
This article is a reply to Richard Lauer's "Is Social Ontology Prior to Social Scientific Methodology?" and an attempt to contribute to the meta-social ontological discourse more broadly. In the first part I will give a rough sketch of Lauer's general project and confront his pragmatist approach with a fundamental problem. The second part of my reply will provide a solution for this problem rooted in a philosophy of the social sciences in practice.
\end{abstract}

\section{Keywords}

meta-ontology, realism, pragmatism, philosophy of science in practice, methodology

This is a reply to Richard Lauer's paper "Is Social Ontology Prior to Social Scientific Methodology?" which appeared in this journal in 2019. ${ }^{1}$ Lauer's paper is a contribution to what can be called "meta-social ontology."

\footnotetext{
${ }^{1}$ I wish to thank Stefano Canali and Richard Lauer for constructive feedback on an earlier draft of this reply.
}

Received 6 February 2020

'Leibniz University Hannover, Hannover, Germany

\section{Corresponding Author:}

Simon Lohse, Centre for Ethics and Law in the Life Sciences (CELLS) \& Institute of Philosophy, Centre for Ethics and Philosophy of Science, Leibniz University Hannover, Otto-Brenner-Str. I, 30159 Hannover, Germany.

Email: lohse@ww.uni-hannover.de 
Meta-social ontology is an emerging field that-in line with its big sister meta-ontology (or "meta-metaphysics," see the essays in Chalmers, Manley, and Wasserman 2009) — examines the purpose, the methods, and the viability of different approaches to social ontology (see Kivinen and Piiroinen 2006; Lohse 2017; van Bouwel and Weber 2008). Lauer's meta-ontological contribution (a) critically assesses mainstream realist approaches to social ontology that are science-directed in that they aim at improving research in the social sciences and (b) presents a (possibly superior) alternative pragmatist approach to social ontology.

In this reply to Lauer I will discuss both aspects of his paper and attempt to contribute to the meta discourse in social ontology more broadly. In the first part I will give a rough sketch of Lauer's general project and confront the presented pragmatist approach with a fundamental problem. The second part of my reply will provide a solution for this problem via the vindication of the approach to social ontology developed in Lohse (2017), which Lauer discusses but (as I shall argue) misconstrues as realist.

\section{Lauer's Project}

Lauer's paper is a valuable contribution to the discussion for at least two reasons. First, it connects recent work in general meta-metaphysics/meta-ontology, analytical ontology, and the philosophy of the social sciences in a fruitful way. Second, it addresses an issue that (still) has not received enough attention, namely the viability of mainstream approaches to social ontology in relation to the social sciences. Lauer's main target are what he calls "Ontology Matters!" (OM!) arguments, that is, arguments that "support the claim that social ontology matters to the achievement of prediction and explanation in social science" (173). ${ }^{2}$ Lauer draws on work going back to Carnap's analysis of ontological questions and (correctly) points out that most OM! arguments are realist in a specific sense: they are based on the conviction that we need to "carve the social world at its joints" (176) to promote success in the social sciences. To achieve this (according to the realists), we need to find out what there really is in the social world, that is, what the right kind of ontological framework is, which can be done by deploying "characteristically philosophical (armchair) methods" (172). Lauer's prime examples for realist OM! approaches of this kind are Searle $(1995,2010)$ and Epstein $(2015,2016)$. As is well known, both think that social ontology is prior to social science research in the realist sense and that we need to build the social sciences on a better

\footnotetext{
${ }^{2}$ Bare page numbers refer to Lauer's paper.
} 
(i.e., Searle's/Epstein's) social ontology to facilitate progress in the social sciences in terms of successful explanations and predictions. ${ }^{3}$

Lauer contrasts the realist approach with a pragmatist version of OM! where social ontology does not aim at carving the social world at its joints but at introducing statements to the social sciences "that enable inferences to predictions and/or explanations, where before we might have lacked the ability to perform such inferences" (183). The key move here is that the introduced statements do not entail an ontological commitment to what there really is. They only serve the instrumentalist function of enabling epistemic operations in the social sciences that can be tested and revised. While Lauer does not argue for the pragmatist approach directly, he clearly thinks that it is superior to its alternative. The main reason he gives for this is that the pragmatist approach is more "economical." It is useful for progress in the social sciences but does not rely on any kind of realism. Realism is not only a notoriously hard to defend position in the context of the social sciences. According to Lauer, it is also not clear on what basis we need to accept the realists' assumption that "cutting the social world at its joints" is required for progress in the social sciences $(173,186)$.

In my view, Lauer's skeptical assessment of the viability of realist OM! arguments is on the right track, especially in light of additional problems for realist social ontologies that claim to be the foundations for research in the social sciences: how can we ever know what the ontology of the social world really is by relying on a priori reasoning and in light of the never-ending disputes in analytical ontology? And why should social scientists care what kinds of ontological frameworks are developed by philosophers? (Lohse 2017, 13f.). Unfortunately, the pragmatist approach presented by Lauer does not really provide a viable alternative for OM! arguments. This can be seen by considering the question of what is left to do under the heading of a pragmatist social ontology. According to Lauer, the only task left is to provide the social sciences with (potentially fruitful) statements that enable new explanations and predictions. But what would that really mean other than thinking of new assumptions to be tested in light of empirical evidence? It seems that this would not entail any kind of ontological reasoning (it is just what social scientist do in their day-to-day research). ${ }^{4}$ There is no analysis of the properties of

\footnotetext{
${ }^{3}$ Lauer also describes my approach to social ontology as realist, although of a more modest and ambiguous kind. The reason for this is that some of my statements do not seem to fit well with his characterization of realist Ontology Matters! (OM!) arguments. In the second part of this article I will attempt to dissolve these ambiguities. "The phrase "ontological reasoning" (or "ontological investigation") should not be understood in the restricted sense of "the study of things as they really are" here, of
} 
social phenomena and their dependency relations, no uncovering of implicit ontological assumptions, no clarification of incoherent ontological assumptions in social science theories, and so on. There is just no discussion of ontological matters of any kind. If this is Lauer's position, it collapses with radically anti-ontological pragmatist positions that attempt to de-ontologize the entire debate and solely focus on operationalizable research questions and methodology (Kivinen and Piiroinen 2006; Tsilipakos 2012; van Bouwel 2004; van Bouwel and Weber 2008).

\section{Ontological Investigations and Philosophy of the Social Sciences in Practice}

As I have attempted to show in Lohse (2017), this is not the only available option though. We can aim for an alternative approach to social ontology that is pragmatist without giving up philosophical investigations that might be fruitful for the social sciences. To see this, it is useful to reconstruct Lauer's analysis of my approach to social ontology and to resolve a number of misunderstandings along the way. Lauer is puzzled as to what my position really is (175). On the one hand, I appear to be a proponent of realist OM! arguments, since I argue for the thesis that substantial ontological investigations can be useful for the social sciences. I even claim that ontology needs to "extend beyond theories" (Lohse 2017). On the other hand, I criticize the analytical approaches of Searle, Epstein, and others as well as their methodology. Apparently, that puts me in the odd position that I want to move beyond social science theories and understand what really exists in the social world (in the "external" sense of the question), but without relying on the traditional approach of analytical ontology. This position does not seem to be coherent.

Fortunately, the (apparent) incoherence of my position can be dissolved. Lauer is right to point out that my approach is highly critical of traditional approaches to social ontology—such as Searle's and Epstein's approach. However, Lauer misunderstands my demand to extend ontological investigations "beyond theories." He thinks that this statement reveals my commitment to a realist approach to social ontology that attempts to present a metaphysical picture of what there really is in social reality. This

course, as this would be tantamount to the realists' approach. My use of the phrase is more innocuous. It is meant to refer to all kinds of analyses of ontological aspects and assumptions of the sciences. In the next paragraphs I will attempt to elucidate this concept of ontological investigations in the context of the social sciences.

${ }^{5}$ Possibly, my incautious use of the phrase "beyond theories" misled Lauer here. It could be read as "over and above theories" in a metaphysical sense which was not what I had in mind. 
interpretation is missing my point though. ${ }^{5}$ My demand to extend beyond theories should rather be understood in light of the methodological stance I articulate in my paper, namely to understand ontology as part of a philosophy of science in practice. This kind of philosophy of science has been pioneered by Ian Hacking, Nancy Cartwright, Hasok Chang, and others (see Soler et al. 2014 for an overview). It aims at paying close attention to developments in the actual sciences and attempts to refocus the philosophical analysis of the epistemic aspects of science. Instead of directing most of the attention at scientific theories and the relationship between theories and reality, philosophers of science in practice analyze scientific theories alongside epistemic practices, such as experimentation in the laboratory, explanatory modeling, and classification practices. This re-orientation introduces new kinds of questions to philosophy of science, which in turn suggest more naturalistic ways of answering them: how do the material aspects of the laboratory interact with experimental design? To what extent does big data research influence scientific classifications in biology? What are the implicit ontological assumptions of explanatory network models in sociology? Answering questions like these requires a detailed analysis of scientific practices (sometimes by deploying empirical social research methods) and opens up new ways of understanding the interplay of epistemic activities and scientific knowledge. In addition (and more to the point of this reply), tackling ontological questions such as the latter two enables us to gain a deeper understanding of factors that influence the different ways that scientists represent the structure of a specific domain (its classification), and of the sometimes hidden "ontological costs" (Peacock 2011) of explanatory practices - that is, the things (including their properties and relations) that need to be assumed to exist for a model to (actually) explain certain phenomena or processes.

Understanding ontological investigations through the lens of a philosophy of the social sciences in practice would likewise mean a re-orientation. It would amount to

the investigation of explicit and implicit ontological assumptions of theories and explanatory frameworks, that is, the investigation of the ontological demands on the world presupposed by scientific theories, models, and related explanatory practices. (Lohse 2017, 15)

This conception is intended as a third way next to (a) realist ontological approaches that attempt to use armchair methods to uncover the true ontological basis of the social world as foundations for the social sciences and (b) pragmatist approaches that aim for abandoning ontological investigations tout court. Ontological investigation as part of a philosophy of the social sciences 
in practice are investigations that take seriously the ontological assumptions and implicit ontological commitments of the social sciences and their epistemic practices, including their less theory-based explanatory activities. It is this inclusion of epistemic practices that I have in mind when I demand to move beyond theories.

Ontological investigations of this kind attempt to analyze and clarify basic assumptions concerning the social world that are presupposed not only by social theories, but also by different explanatory frameworks and explanatory practices (e.g., agent-based modeling of social phenomena). While this approach takes seriously the ontological assumptions and implicit commitments of the social sciences, this does not imply a realist commitment to the respective assumptions and commitments. In fact, the approach is open to the possibility of a plurality of incompatible social ontologies and is not wedded to the ideas that there is only one right way of conceptualizing the social world or that we can approximate a true conceptualization of the social world. ${ }^{6}$ Moreover, the approach is not in the business of building (better) social ontologies itself, although — as I will suggest below-ontological investigations in line with a philosophy of the social sciences in practice may contribute to the integration of different social ontologies via conceptual clarification and immanent critique of theories and explanatory frameworks.

This "third way" of doing ontology is nothing new. It has rather become one of the mainstream options in the philosophies of the (empirical) special sciences. Philosophers of physics do not attempt to develop the ontological foundations of physics from scratch (this would be considered absurd). They aim for example to understand the ontological implications of different interpretations of quantum physical experiments or the ontological status of dark matter as an element of the standard model of the universe. Likewise, (most) philosophers of the life sciences do not attempt to theorize about the nature of biological phenomena in the armchair. They rather analyze the ontological presuppositions and/or implications of different epistemic activities in the life sciences. In many cases, these kinds of ontological investigations are not science-directed in the sense that they are not meant to be relevant for scientific success. But they can nevertheless be helpful for practicing scientist, and sometimes they are indeed intended to contribute to empirical success in the sciences (e.g., in the context of interdisciplinary research on the foundations of physics and cosmology).

\footnotetext{
${ }^{6}$ This may be the key difference between Daniel Little's and my approach (see his paper in this issue of Philosophy of the Social Sciences and Little 2009).
} 
In the philosophy of the social sciences, the analysis of the ontological assumptions of social scientific theories, models, and epistemic practices is far from being a mainstream option. Most work in the philosophy of the social sciences is ontological in the sense of Epstein and Searle. It is, in other words, not really concerned with ontological aspects of the existing social sciences (the same applies to much of the ontological individualism/holism discourse in the philosophy of the social sciences). Alternatively, philosophers of the social sciences address (real) epistemological and methodological issues of the social sciences without any ontological focus. ${ }^{7}$ This is a peculiar situation for two reasons. First, many social scientists have been or are quite interested in ontological issues of their own disciplines (Marx, Bourdieu and Critical Realists, to name but a few). Second, many of the longlasting disputes between different explanatory frameworks in the social sciences have an implicit or explicit ontological dimension. Bourdieu's practice-theoretical framework, the explanatory framework in Analytical Sociology, and Neo-Marxist approaches not only have different epistemic aims and diverging methodological affinities (e.g., for micro- or macroexplanations), they also entail different ontological assumptions regarding individual agents and social phenomena (e.g., distinct individual agents in Analytical Sociology vs. socially constituted agents in Bourdieu's framework). This fact can and should, I believe, motivate philosophers of the social sciences to investigate ontological aspects of their target disciplines alongside epistemological and methodological questions. For one thing, this would be an important contribution to the main descriptive task of the philosophy of the social sciences: to understand the social sciences, their specific features (such as their multiparadigmatic structure) and related aspects from an epistemic point of view. For another thing, this could also be a normative contribution that is fruitful for the social sciences. A critical comparative analysis of the ontological assumptions of different explanatory frameworks could, for example, show that some of the prima facie deeply conflicting ontological assumptions in the social sciences turn out to be shallow-and hence: compatible - if reconstructed charitably and in light of the actual epistemic interests of social scientists (Lohse 2019). ${ }^{8}$ In this and similar cases, ontological investigations to not provide the basis for better explanations and predictions in the social sciences, but they help clarifying the actual ontological assumptions of different explanatory frameworks. This can support

\footnotetext{
${ }^{7}$ See Kincaid (2016) for an instructive exception to this.

${ }^{8}$ Such an analysis can, of course, benefit from the conceptual tools of analytical ontology, such as those used in the analysis of different types of ontological dependence relations (Tahko and Lowe 2016).
} 
inner scientific discourse in the social sciences and foster "epistemic defragmentation," which could contribute to scientific success in the long runOntology Matters!

In other cases, however, the analysis of ontological assumptions in the social sciences may indeed contribute to explanatory and/or predictive success, albeit in a more indirect way than suggested by Lauer. The case of organizational ecology can serve as an example for this claim here, since I already discussed it as an example in Lohse (2017, 16f.), and since Lauer uses this discussion for the purposes of his paper (184f.). Organizational ecology aims to explain, amongst other things, why certain kinds of organizations survive better in different kinds of environments. For this purpose, they (e.g., Hannan and Freeman 1989) rely heavily on Darwinian selection mechanisms on the population level as explanatory factors. In my paper, I refer to Reydon and Scholz (2009) who demonstrate that this explanatory practice is illusive because the proposed evolutionary selection mechanism can only work with populations that are able to evolve in a Darwinian sense-which organizational populations cannot. Lauer thinks that this critique is unhelpful:

Instead of concerning ourselves with whether there really are such populations, we may ask about the empirical merits of moving to a view of organizations that treats them as amenable to evolutionary styles of explanation. (14)

This instrumentalist response might work if we merely wanted to predict organizational behavior. We could just ask then which assumptions generate the most successful predictions, without having to worry too much about the ontological adequacy of the respective assumptions. However, organizational ecologists are also interested in a Darwinian explanation of certain patterns of organizational behavior. It is this explanatory aim - to provide an evolutionary how-actually explanation - that presupposes certain properties of the respective organizational populations. If we want to explain changes in organizational populations in terms of Darwinian selection mechanisms, these populations need to be able to evolve in a Darwinian sense. Otherwise there is an ontological mismatch that makes a Darwinian explanation impossible. In this case, a conceptual analysis of the required ontological commitments of the explanatory framework in question contributes to better explanatory practices in the social sciences-Ontology Matters! Note, that this does not imply any kind of realist commitment or presenting "a priori challenges" (177) to social scientists. The outlined ontological critique of organizational ecology is entirely immanent to its explanatory project and is based on the ontological mismatch between populations of living things and organizations. 
There are many more cases, where the analysis and clarification of ontological assumptions and implicit commitments of social theories, frameworks, and less theory-based explanatory practices may contribute to progress in the social sciences: an analysis of different taxonomies of social phenomena in different areas of the social sciences may contribute to cross-paradigm communication, the clarification of ontological ambiguities in mechanistic explanations may improve their explanatory force, and so on (Lohse 2017, 18ff.). This, however, would mean a radical shift away from analytical ontology and toward a methodology in line with a philosophy of the social sciences in practice. In my view, this approach to social ontology is pragmatist enough without giving up a distinctly philosophical perspective, a perspective that can have a clarifying impact on the social sciences.

\section{Declaration of Conflicting Interests}

The author(s) declared no potential conflicts of interest with respect to the research, authorship, and/or publication of this article.

\section{Funding}

The author(s) received no financial support for the research, authorship, and/or publication of this article.

\section{References}

Chalmers, D., D. Manley, and R. Wasserman, eds. 2009. Metametaphysics: New Essays on the Foundations of Ontology. Oxford: Oxford University Press.

Epstein, B. 2015. The Ant Trap: Rebuilding the Foundations of the Social Sciences. Oxford: Oxford University Press.

Epstein, B. 2016. "A Framework for Social Ontology." Philosophy of the Social Sciences 46 (2): 147-67. https://doi.org/10.1177/0048393115613494

Hannan, M. T., and J. Freeman. 1989. Organizational Ecology. Cambridge: Harvard University Press.

Kincaid, H. 2016. "Debating the Reality of Social Classes." Philosophy of the Social Sciences 46 (2): 189-209. https://doi.org/10.1177/0048393115614254

Kivinen, O., and T.Piiroinen. 2006. "Toward Pragmatist Methodological Relationalism: From Philosophizing Sociology to Sociologizing Philosophy." Philosophy of the Social Sciences 36 (3): 303-29. https://doi.org/10.1177/0048393106289794

Lauer, R. 2019. “Is Social Ontology Prior to Social Scientific Methodology?" Philosophy of the Social Sciences 49(3): 171-189. https://doi.org/10.1177/0048393119840328

Little, D. 2009. "The Heterogeneous Social: New Thinking about the Foundations of the Social Sciences." In Philosophy of the Social Sciences: Philosophical Theory and Scientific Practice, edited by C. Mantzavinos, 154-78. Cambridge: Cambridge University Press. 
Lohse, S. 2017. "Pragmatism, Ontology, and Philosophy of the Social Sciences in Practice." Philosophy of the Social Sciences 47 (1): 3-27. https://doi. org/10.1177/0048393116654869

Lohse, S. 2019. Die Eigenständigkeit des Sozialen. Zur ontologischen Kritik des Individualismus. Heidelberg: Mohr Siebeck.

Peacock, H. 2011. "Two Kinds of Ontological Commitment." The Philosophical Quarterly 61 (242): 79-104. https://doi.org/10.1111/j.1467-9213.2010.665.x

Reydon, T. A. C., and M. Scholz. 2009. "Why Organizational Ecology Is Not a Darwinian Research Program.” Philosophy of the Social Sciences 39 (3): 408-39. https://doi.org/10.1177/0048393108325331

Searle, J. R. 1995. The Construction of Social Reality. New York: Free Press.

Searle, J. R. 2010. Making the Social World: The Structure of Human Civilization. Oxford: Oxford University Press.

Soler, L., S. Zwart, M. Lynch, and V. Israel-Jost, eds. 2014. Science after the Practice Turn in the Philosophy, History, and Social Studies of Science. New York: Routledge.

Tahko, T. E., and E. J. Lowe. 2016. “Ontological Dependence.” In The Stanford Encyclopedia of Philosophy (Winter 2016 Edition), edited by E. N. Zalta. Metaphysics Research Lab, Stanford University. https://plato.stanford.edu/ archives/win2016/entries/dependence-ontological/

Tsilipakos, L. 2012. "The Poverty of Ontological Reasoning." Journal for the Theory of Social Behaviour 42 (2): 201-19.

van Bouwel, J. 2004. "Individualism and Holism, Reduction and Pluralism: A Comment on Keith Sawyer and Julie Zahle.” Philosophy of the Social Sciences 34 (4): 527-35. https://doi.org/10.1177/0048393104269198

van Bouwel, J., and E. Weber. 2008. "De-ontologizing the Debate on Social Explanations: A Pragmatic Approach Based on Epistemic Interests." Human Studies 31 (4): 423-42. https://doi.org/10.1007/s10746-008-9102-0

\section{Author Biography}

Simon Lohse is a postdoctoral research fellow at Leibniz University Hannover, Germany. He has a background in social and educational science and holds a PhD in philosophy of science. He is primarily interested in topics in philosophy of the social sciences, meta-philosophy of science, and in questions at the junction of philosophy of science, bioethics, and science studies in the context of animal-based life science research. 